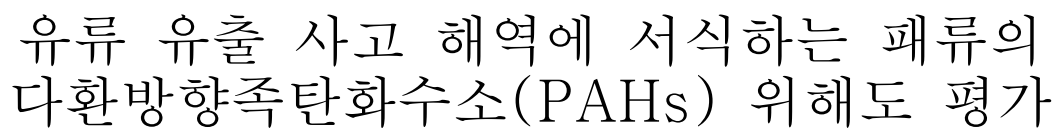

\author{
김풍호*·김민정·조미라·이두석·송기철·변한석·조기채 ${ }^{1}$ \\ 박광재 ${ }^{2} \cdot$ 전제천 ${ }^{3} \cdot$ 윤호동 \\ 국립수산과학원 식품안전과, ${ }^{1}$ 남동해수산연구소, ${ }^{2}$ 갯벌연구소, ${ }^{3}$ 전략양식연구소
}

\title{
Polycyclic Aromatic Hydrocarbons Hazard Assessment of Shellfish due to Oil Spill Accidents
}

\author{
Poong-Ho Kim*, Min-Jeong Kim, Mi-ra Jo, Doo-Seog Lee, \\ Ki-cheol Song, Han-Seok Byun, Kee-Chae Cho', Kwang-Jae Park ${ }^{2}$, \\ Je-Cheon $\mathrm{Jun}^{3}$ and Ho-Dong Yoon \\ Food safty Division, National Fisheries Research and \\ Development Institute, Busan 619-705, Korea \\ ${ }^{1}$ Southeast Sea Fisheries Reserch Institute, NFRDI, Tongyeong 650-943, Korea \\ ${ }^{2}$ Costal Wetland Research Institute, NFRDI, Gunsan 573-882, Korea \\ ${ }^{3}$ Aquaculture Research Institute, NFRDI, Busan 619-705, Korea
}

On 7 December 2007, about 12,547 kL of crude oil spilled from the Hong Kong registered tanker Hebei Spirit along the west coast of the Republic of Korea, including Taean-gun, Chungcheongnamdo Province. This study evaluated the safety of seafood collected from the coastal area polluted by the crude oil. The range of total polycyclic aromatic hydrocarbons ( $\left.\sum \mathrm{PAHs}\right)$ at 22 stations was 3.9-37.1 ng/g. The concentration of $\Sigma$ PAHs was higher in oysters, Crassoatrea gias, than that in short-necked clams, Ruditapes philippinarum. Benzo(a)pyrene, a highly toxic PAH, ranged from $0.07-1.47 \mathrm{ng} / \mathrm{g}$, which did not exceed the European Union regulatory limit for benzo(a)pyrene. The toxicity equivalent of benzo(a)pyrene in oysters and short-necked clams was $0.49-1.70$ and $0.09-1.01 \mathrm{ng} / \mathrm{g}$, respectively. The estimated life time cancer risk was very low, i.e., $1.31 \times 10^{-8}$ for the oysters and $6.9 \times 10^{-9}$ for the short-necked clams. The body burden of PAHs in bivalves originated mostly from petroleum contamination, but the levels was not sufficiently high to harm human health.

Key words: Polycyclic aromatic hydrocarbons, PAHs, Shellfish, Hazard assessment, Oil spillage

서 론

다환 방향족 탄화수소 $(\mathrm{PAHs})$ 는 두 개 이상의 벤젠 고리로 이루어진 유기화합물로 벤조피렌 등의 많은 부류의 화합물로 이루어져 있으며, 유기물질 등의 불완전연소로 발생된다. 2007년 12월 우리나라에서 가장 큰 해양 원유유출사고가 서해 안에서 발생되었다. 이 사고로 약 $12,547 \mathrm{~kL}$ 의 원유가 우리나 라 서해안을 오염시켰으며, 조간대에 사는 서식생물의 생존에 도 큰 영향을 미쳤다. 해양 오염의 원유 유출 사고로 인하여 오염된 수산물을 섭취하는 사람에게는 PAHs에 의한 독성으로 발암성 및 돌연 변이적 잠재력을 빠르게 증가시키는 것으로 알려져 있다 (Gelboin, 1980; Pelkonene and Nebert, 1982). 해양 유류 오염사고로 인해 수산생물에 독성을 끼치는 영향을 초래 하기 때문에 (Bingham and Falk, 1969) 원유 유출 지역으로부 터 다양한 수산생물들에 대한 PAHs의 오염정도를 분석하고 사람에게 끼치는 위해도 평가를 수행하고 있다 (Law and Biscaya, 1994; Boehm and Farrington, 1984). 특히 PAHs 중에서

*Corresponding author: phkim@nfrdi.go.kr
도 벤조피렌은 잔류기간도 길고 독성도 강하여 세계적으로 관심을 받고 있는 내분비계 장애물질이면서 발암성물질로 Codex나 FAO/WHO의 위해성 평가로 우선순위 목록에 포함 되어 있고 국제암연구소 (IARC; International Agency for Research on Cancer)는 최근 벤조피렌을 Group 1의 확인된 인체발암물질 (carcinogenic to humans)로 등급을 상향조정하 였다 (EC, 2002; IARC, 2006; US EPA, 1993).

벤조피렌에 단기간에 걸쳐 다량으로 노출되었을 경우에는 적혈구가 파괴되어 빈혈을 일으키고, 면역계가 저하되는 것으 로 알려져 있고, 장기간 노출되었을 때에는 발암과 돌연변이 를 일으킬 수 있기 때문에 (Kim et al., 1999) 유류유출 사고해역 에서는 수산물 안전성 조사를 위하여 $\mathrm{PAHs}$ 를 분석하고 있다.

$\mathrm{PAHs}$ 는 유기물질이 불완전 연소되는 과정에서 생성되기 때문에 그 오염원이 매우 다양한 물질이다. 주로 대기오염, 환경오염으로 인해 공기, 토양에서도 발견되고 농산물이나 어패류 등 조리나 가공을 하지 않은 식품에도 존재하는 것으 로 알려져 있다. 유류유출사고 해역에서 생산되는 수산물은 $\mathrm{PAHs}$ 의 잔류성과 발암성 때문에 $\mathrm{PAHs}$ 의 잔류농도를 이용하 
여 수산물의 안전성을 평가하고 있으며, 특히 발암성을 가질 수 있는 PAHs 성분 중에서 독성이 가장 강한 벤조피렌을 기준으로 등가치를 부여한 환산값을 이용하고 수산물의 안전 성을 평가하고 있다.

본 연구에서는 원유유출 사고해역의 인근에 서식하고 있는 패류에 안전성을 평가하기 위하여 $\mathrm{PAHs}$ 의 함량을 분석하고, 오염물질의 유입이 원유유출에 따른 근원인지를 지문법을 통해 알아내고자 하였다. 또한 이를 토대로 유류유출 해역에 서 생산되는 패류의 섭취를 통한 PAHs의 인체 노출량에 의한 초기발암 위해도 평가를 수행하였다.

\section{재료 및 방법}

\section{시료 채취 지역}

태안군 및 서산시 연안 유류오염사고 인근해역에서 양식되 고 있는 굴 및 바지락을 채취하여 시료로 사용하였다. 채취장 소는 태안읍의 어도 (ED), 소원면의 파도리 (PDR), 이원면의 의항리 (EHR), 삼동 $(\mathrm{SD})$, 활곡 $(\mathrm{WG})$, 당산 $(\mathrm{DS})$, 사창 $(\mathrm{SC})$, 대산읍의 오지 $(\mathrm{OG})$, 웅도 $(\mathrm{WD})$, 지곡면의 중앙 $(\mathrm{JA})$, 가로림 $(\mathrm{GLL})$, 팔봉면의 팔봉 $(\mathrm{PB})$, 고파도 $(\mathrm{GPD})$, 남면의 진산리 (JSR), 원청리 (WCR), 드르니 (DLN), 안면읍의 신야1리 $(\mathrm{SY} 1 \mathrm{R})$, 방포 $(\mathrm{BP})$, 중장 1리 $(\mathrm{JJ} 1 \mathrm{R})$, 고남면의 장동 $(\mathrm{JD})$, 옷점 $(\mathrm{OJ})$, 가경주 $(\mathrm{KKJ})$ 등 22 개 지점이었다.

분석 대상 물질

유류 오염사고지역에서 분석되는 16종 PAHs는 Naphthalene (NPTHL), Acenaphthalene (ANCPL), Acenaphthene (ACNPN), Fluorene (FLURN), Phenanthrene (PHEN), Anthracene (ANTHR), Fluoranthene (FLRTH), Pyrene (PYR), Chrysene (CHRY), Benzo(b)fluoranthene (BbF), Benzo(k)fluorathene (BkF), Benzo(a)pyrene (BaP), Dibenz(a,h) anththracene (DahA), Benzo(g,h,I)peryline (BghiP), Indeno (1,2,3cd)pyrene (I123cdP) 이다.

시료 채취 및 분석

패류시료에서 PAHs의 분석은 Moon et al. $(2001,2004)$ 의 방법에 따라 분석하였으며, 분석에 사용된 시약은 특급 및 잔류농약 분석용을 사용하였다. 굴 및 바지락 양식장에서 채 취한 시료는 냉장 상태를 유지하여 실험실로 이동시켰으며, 채취된 시료는 실험실에서 탈각 한 후 분쇄하여 $10 \mathrm{~g}$ 을 정확히 동결건조 (Eyela, FDU-2100, Japan)하여 실험에 사용하였다. 동결 건조된 시료를 분액여두에 옮겨 $1 \mathrm{~N}$ 수산화칼륨과 에탄 올 1:9로 만든 용액 $100 \mathrm{~mL}$ 를 넣고 내부표준물질 (Semivolatile Internal Standard Mix., SUPELCO, USA)를 $100 \mu \mathrm{L}$ 첨가하고 2시간 진탕하였다. 그리고 세정수 $40 \mathrm{~mL}$ 와 핵산 $75 \mathrm{~mL}$ 를 넣고 10 분간 다시 진탕하는 과정을 2 번 하였다. 진탕 추출 후 하층은 버리고 상층의 용액을 합한다. 합해진 상층 용액에 세정수 $50 \mathrm{~mL}$ 를 넣고 수층 분리하는 과정을 2 번 반복하였다. 무수황산나트륨을 통해 수분을 제거한 후 진공회전농축기 (EYELA, Japan) 및 질소를 이용하여 $5 \mathrm{~mL}$ 까지 농축하였다.
농축한 추출액은 다층 실리카겔 칼럼크로마토그래피법 (Multi-layer silica-gel column chromatography)으로 정제하였 다. 즉, 실리카 칼럼에 $1-2 \mathrm{~cm}$ 솜을 깔고 $2 \mathrm{~g}$ 정도의 무수황산, $5 \mathrm{~g}$ 실리카겔, 다시 무수황산 $2 \mathrm{~g}$ 정도를 넣어 헥산으로 채운 후 질소압에 의해 공극률을 줄인 칼럼을 준비한 다음 농축한 시료 추출액을 천천히 주입하고 헥산으로 세정한 다음 디클로 로메탄과 헥산 (1:9)용액 $50 \mathrm{~mL}$ 로 최종 용출하였다. 그 용출액 을 질소로 $3 \mathrm{~mL}$ 가 되도록 다시 농축시킨 후 노난 (잔류농약분 석용, Fluka) $50 \mu \mathrm{L}$ 을 첨가하고 24시간 정도 노난만 남아있을 때까지 방치 시킨 후 노난으로 $100 \mu \mathrm{L}$ 정용하여 분석하였다. 시료 중의 PAHs는 GC-MSD (Agilent 5973, U.S.A.)가 부착된 가스크로마토그래피를 사용하여 Table 1과 같은 조건으로 분 석하였다. Column은 DB-5 MS column (length 30 m, i.d. 0.25 $\mathrm{mm}$, film thickness $0.25 \mathrm{Am}, \mathrm{J} \& \mathrm{~W}$ Scientific, Folsom, CA)을 사용하였고 column oven의 온도는 $80^{\circ} \mathrm{C}$ 에서 1 분간 정체 후 $280^{\circ} \mathrm{C}$ 까지 분당 $5^{\circ} \mathrm{C}$ 씩 상승시켜 $280^{\circ} \mathrm{C}$ 까지 승온시킨 후 $10^{\circ} \mathrm{C}$ 씩 상승시켜 $300^{\circ} \mathrm{C}$ 에서 10 분간 정체 시켰다. 이때 carrier gas는 helium $(1 \mathrm{~mL} / \mathrm{min})$ 을 사용하였고, Injector 온도는 $250^{\circ} \mathrm{C}$ 로 하였 다. 정량분석은 질량분석기의 SIM (Selected Ion Monitoring (SIM) 모드를 이용하여 분석하였다.

Table 1. Operation conditions GC-MSD for PAHs

\begin{tabular}{cl}
\hline Items & \multicolumn{1}{c}{ Conditions } \\
\hline Instrument & Agilent GC-MSD (Agilent 5973) \\
Column & DB-5MS (30 m length, 0.25 mm inner diameter, \\
& $0.25 \mu \mathrm{m}$ film thickness, J\&W Sci., USA) \\
Injector type & splitless \\
Carrier gas & Helium, $1.0 \mathrm{~mL} / \mathrm{min}$ (Constant Flow) \\
lonization mode & $\mathrm{El}+$ \\
Injector temperature & $250^{\circ} \mathrm{C}$ \\
Ion Source temp. & $230^{\circ} \mathrm{C}$ \\
Qudrople temp. & $150^{\circ} \mathrm{C}$ \\
Column temperature & $80^{\circ} \mathrm{C}(1 \mathrm{~min})-5^{\circ} \mathrm{C} /$ min - $280^{\circ} \mathrm{C}-10^{\circ} \mathrm{C} / \mathrm{min}-$ \\
Quantitation method & $300^{\circ} \mathrm{C}(10 \mathrm{~min})$ \\
Injection volume & $1 \mu \mathrm{L}$ \\
\hline
\end{tabular}

위해성 평가

내분비 장애물질인 PAHs는 어류와 패류는 환경으로부터 먹이 섭취를 통해 소량으로 흡수 될 수 있으며 (Gold et al., 1986; Kim et al., 1999), 인위적인 원유 유출의 결과뿐 만 아니 라 화석 연료를 사용하고 있는 산업공정, 자동차 연료 및 배출 가스, 나무의 연소, 담배 및 그을린 음식 등의 자연발생적으로 도 노출되어 있다 (Lee and Page, 1997). 일반적으로 인위적인 오염원이 자연적 오염원 보다 훨씬 많은 양의 PAHs를 방출하 고 있기 때문에 위해성 평가가 필요하다고 알려져 있다 (Busby et al., 1989; Cavalieri et al., 1989; Speer et al., 1990). 특히 패류는 어류에 비해 유기체에 의해 배설되고 산화능력을 가지 고 있지 않기 때문에 PAHs 축적률이 높아 본 연구에서는 패류 중 바지락과 굴을 대상으로 $\mathrm{PAHs}$ 에 대한 위해성 평가를 수행하였다(IARC, 1983; Petry et al., 1996; Portter and 
Simmons, 1998). PAHs의 위해성 평가는 벤조피렌의 발암력을 기준으로 PAHs의 개별 congener들에 대한 TEFs값을 곱하여 나타낸 벤조피렌 독성등가치를 주로 사용되고 있다 (US EPA, 1979; US EPA, 1988; US EPA, 1993; WHO, 1995; Tsai et al., 2001). PAHs 위험 평가를 위해 벤조피렌의 발암력에 의해 $\mathrm{PAHs}$ 의 혼합물 각각의 $\mathrm{TEF}$ 의 값을 U.S. EPA자료을 인용하여 Table 2에 나타내었다.

Table 2. Proposed toxic equivalency factors for individual PAHs

\begin{tabular}{lc}
\hline \multicolumn{1}{c}{ Compound } & USEPA(1993) \\
\hline Chrysene & 0.001 \\
Benzo(k)fluoranthene & 0.01 \\
Indeno(1,2,3-c,d)pyrene, Benzo(b)fluoranthcene, & 0.1 \\
Benzo(a)anthracene & 1.0 \\
Benzo(a)pyrene, Dibenzo(a,h)anthracene & \\
\hline
\end{tabular}

\section{인체노출평가}

수산 어패류를 통한 PAHs의 인체 노출 평가는 발암물질의 인체 노출 평가 방법에 준하였다. 아래의 수식은 식품 섭취에 의한 $\mathrm{PAHs}$ 의 만성 1 일 인체 노출량 계산을 나타낸 것이다 (IARC, 1983; IARC, 1985; OEHHA, 2005).

만성 1 일 인체노출량 $(\mu \mathrm{g} / \mathrm{kg} / \mathrm{day})=\frac{C F i \times I R i \times E D}{B W \times A T}$

$\mathrm{CFi}$ : 식품 (i) 중 $\mathrm{PAHs}$ 농도 $(\mu \mathrm{g} / \mathrm{kg})$

IR : 식품 (i) 섭취율 (Ingestion rate, g/day)

$\mathrm{ED}$ : 노출기간 (exposure duration, year)

$\mathrm{BW}$ : 체중 (Body weight, $\mathrm{kg}$ )

AT : 평균수명 (average time, year)

굴 및 바지락의 PAHs 량을 벤조피렌 등가치로 환산한 값을 적용하였고, 수산물 중 1 일 평균 어패류 섭취량을 활용하였으 며, 평균수명은 70 세, 평균체중은 $60 \mathrm{~kg}$ 으로 하였다.

\section{위해도 결정}

유류유출 사고해역에서 생산된 패류 섭취를 통한 $\mathrm{PAHs}$ 의 인체 노출량으로부터 발생할 수 있는 초기발암 위해도는 만성 1 일 인체노출량과 $\mathrm{PAHs}$ 중 독성이 가장 강한 벤조피렌의 발암 력 $7.3(\mathrm{mg} / \mathrm{kg} / \mathrm{day})^{-1}$ 을 (US EPA, 2004) 곱하여 산출하였다.

\section{결과 및 고찰}

유류유출 사고해역의 패류 중 PAHs 함량

서해안 패류의 수산물 안전성을 평가하고, 유류유출 사고의 영향을 받은 해역에서 수산물을 채취할 수 있는지, 조업재개 가 가능한지를 평가하기 위하여 서해안 유류유출 사고가 발생 한지 6개월이 지난 후에 해역에 위치해 있는 패류생산해역 22 개 지점에서 굴 및 바지락등 패류를 채취하여 분석한 총 PAHs, 벤조피렌 및 벤조피렌 등가치를 Table 3에 나타내었다. 유류유출 사고 인근해역에서 서식하고 있는 굴 및 바지락양식
Table 3. Concentration of $\Sigma \mathrm{PAH}$ and $\mathrm{BaP}$ and its Toxicity equivalent (TEQ) for Benzo(a)Pyrene at each sample station in West sea, Korea

\begin{tabular}{|c|c|c|c|c|}
\hline Shellfish & areas & PAHs & $\mathrm{BaP}$ & TEQ of $\mathrm{BaP}$ \\
\hline \multirow{9}{*}{ Oyster } & Eeo-do (ED) & 19.9 & 0.86 & 1.01 \\
\hline & Samdong (SD) & 20.0 & 0.64 & 0.74 \\
\hline & Dangsan (DS) & 20.5 & 0.94 & 1.10 \\
\hline & Sachang (SC) & 15.9 & 0.71 & 0.83 \\
\hline & Woong-do (WD) & 29.4 & 1.47 & 1.70 \\
\hline & Jungang (JA) & 37.1 & 0.56 & 0.64 \\
\hline & Jinsan (JS) & 16.0 & 0.74 & 0.88 \\
\hline & Wonchong-ri (WCR) & 12.0 & 0.41 & 0.49 \\
\hline & Eohang-ri (EHR) & 11.9 & 0.63 & 0.72 \\
\hline \multirow{16}{*}{$\begin{array}{l}\text { Short neck } \\
\text { clams }\end{array}$} & Eeo-do (ED) & 7.0 & 0.24 & 1.01 \\
\hline & Samdong (SD) & 6.9 & 0.17 & 0.26 \\
\hline & Whalgok (WG) & 7.1 & 0.17 & 0.24 \\
\hline & Dangsan (DS) & 8.9 & 0.27 & 0.38 \\
\hline & Otjem (OJ) & 19.0 & 0.17 & 0.23 \\
\hline & Jungang (JA) & 10.8 & 0.12 & 0.15 \\
\hline & Garolim (GLL) & 13.5 & 0.34 & 0.46 \\
\hline & Palbong (PB) & 35.8 & 0.21 & 0.26 \\
\hline & Gopa-do (GPD) & 13.4 & 0.34 & 0.46 \\
\hline & Wonchong-ri (WCR) & 12.4 & 0.19 & 0.25 \\
\hline & Deureuni (DRN) & 8.0 & 0.14 & 0.18 \\
\hline & Sanya1-ri (SY1R) & 3.9 & 0.07 & 0.09 \\
\hline & Jungjang1-ri (JJ1R) & 8.5 & 0.19 & 0.28 \\
\hline & Jangdong (JD) & 9.8 & 0.13 & 0.18 \\
\hline & Kakeongju (KKJ) & 8.0 & 0.16 & 0.24 \\
\hline & Pado-ri (PDR) & 12.3 & 0.25 & 0.32 \\
\hline
\end{tabular}

장 22개 지점의 총 $\mathrm{PAHs}$ 의 전체 잔류농도의 합은 3.9-37.1 $\mathrm{ng} / \mathrm{g}$ wet weight의 수준으로 나타났으며, 전체 조사해역의 지 곡면 중앙 $(\mathrm{JA})$ 지점에서 채취된 굴이 가장 높은 $\mathrm{PAHs}$ 잔류량 을 나타내었으며, 신야 1리 (SY1L)에서 채취한 바지락에서 가장 낮은 수준으로 나타났으며, 대체적으로 굴 (11.9-37.1 $\mathrm{ng} / \mathrm{g}$ )이 바지락 (3.9-35.8 ng/g)에 비하여 총 PAHs의 잔류농도 가 높았다. Moon et al. (2004) 등이 조사한 우리나라 연안에 서식하는 이매패류의 평균 PAHs의 총합은 13.9-224 ng/g dry weight 라고 보고한 바 있으며, 이를 습식량으로 환산하면 이번 조사와 크게 다르지 않은 것으로 파악되었다. 따라서 조사시점까지 유류유출사고로 인하여 서해안 인근 패류양식 장에서 양식중인 패류가 유출된 유류의 영향으로 크게 받지 않고 있다고 생각된다.

PAHs 중 벤조피렌은 잔류 기간이 길고, 독성이 강하기로 알려져 있지만, 우리나라를 비롯하여 일본 미국등에서는 $\mathrm{PAHs}$ 에 대한 잔류허용기준이 없으나, $\mathrm{EU}$ 에서는 식품 중 벤조 피렌의 최대잔류허용기준치를 규정하고 있다. 이 규정에 의하 면 이매패류중의 벤조피렌 최대허용잔류량은 $10 \mathrm{ng} / \mathrm{g}$ 이다 (EC, No 1881/2006). 조사해역에서 채취된 굴의 벤조피렌 잔류 농도는 $0.41-1.47 \mathrm{ng} / \mathrm{g}$ )이었으며, 바지락은 $0.07-0.34 \mathrm{ng} / \mathrm{g}$ 의 수준이었으며, 조사지점별로 살펴보면 대산읍 웅도 (WD)의 굴은 $1.47 \mathrm{ng} / \mathrm{g}$, 이원면 당산 (DS)의 굴은 $0.94 \mathrm{ng} / \mathrm{g}$, 태안읍 어도 (ED)의 굴은 $0.87 \mathrm{ng} / \mathrm{g}$ 으로 비교적 높은 수준이었지만, 
$\mathrm{EU}$ 에서 정하고 있는 기준에는 아주 낮은 안전한 수준임을 확인하였다. 또한 EPA에서는 PAHs 중 benz(a)anthracene, benzo(a)pyrene, benzo(b)fluoranthrene, benzo(k)fluoranthrene, chrysene, dibenz(a,h)anthracene and indeno(1,2,3-cd)pyrene. 발 암력이 강한 화합물로 분류하고 있다 (US EPA, 1993). 그리고 $\mathrm{EPA}$ 와 $\mathrm{WHO}$ 에서는 독성이 강한 벤조피렌의 $\mathrm{TEF}$ (Toxicity Equivalency Factor) 값을 1로 하여 다른 PAHs에 대해 상대적 $\mathrm{TEF}$ 값을 정하고 있다. $\mathrm{PAHs}$ 함량에 이 값을 적용하여 다시 말해, 농도에 TEF값을 곱하여 TEQ (Toxic Equivalent) 값으로 나타내었다. 수산물 안전성 평가를 위해 벤조피렌 등가치를 측정하면 굴은 대산읍 웅도 $(\mathrm{WD})$ 의 굴은 $1.70 \mathrm{ng}-\mathrm{TEQ}_{\mathrm{BaP}} / \mathrm{g}$, 이원면 당산 (DS)의 굴은 $1.10 \mathrm{ng}-\mathrm{TEQ} \mathrm{Bap} / \mathrm{g}$, 태안읍 어도 (ED) 의 굴은 $1.01 \mathrm{ng}-\mathrm{TEQ}_{\mathrm{BaP}} / \mathrm{g}$ 으로 다른 지역에 비해 다소 높은 잔류량을 나타내었으며, 바지락은 어도 $(\mathrm{ED})$ 지역에서 1.01 $n g-\mathrm{TEQ}_{\mathrm{BaP}} / \mathrm{g}$ 이 잔류하였다. 미국의 유류유출사고 지역에서 패류의 안전성은 벤조피렌 등가치를 이용하고 평가 하고 있으 며, 오염사고 및 지역에 따라 패류안전과 수산물의 조업재게 를 위한 벤조피렌 등가치를 다르게 적용하고 있다. 미국의 New carissa 기름유출사고해역에서 패류는 벤조피렌 등가치 가 $10 \mathrm{ng}-\mathrm{TEQ}_{\mathrm{BaP}} / \mathrm{g}$ 이하면 안전한 것으로 판단하였으며, 45 $\mathrm{ng}-\mathrm{TEQ}_{\mathrm{BaP}} / \mathrm{g}$ 이상이면 패류는 이 지역에서 안전하지 않은 것 으로 판단하였으며, 지속적인 모티터링이 필요하다고 하였다. Kure 오일 오염사고 지역에서는 모든 시료에서 벤조피렌 등가 치가 $5 \mathrm{ng}-\mathrm{TEQ}_{\mathrm{BaP}} / \mathrm{g}$ 이하면 패류양식장에서 조업을 허용하였 으며, 5 이상 $34 \mathrm{ng}-\mathrm{TEQ}_{\mathrm{BaP}} / \mathrm{g}$ 이하는 조업재개를 위하여 평가 를 실시하고, 만약에 $34 \mathrm{ng}-\mathrm{TEQ}_{\mathrm{BaP}} / \mathrm{g}$ 를 초과하면 추가적인 조사와 환경모니터링이 수반되어야 한다고 하였다 (Law et al., 2002; Kelly et al., 2008). 따라서 현재까지 우리나라 서해안 에서 채취한 패류는 벤조피렌 등가치가 $2 \mathrm{ng}-\mathrm{TEQ}_{\mathrm{BaP}} / \mathrm{g}$ 이하의 수준으로 검출되어 수산물 안전성에는 큰 문제가 없는 것으로 추정되었다.

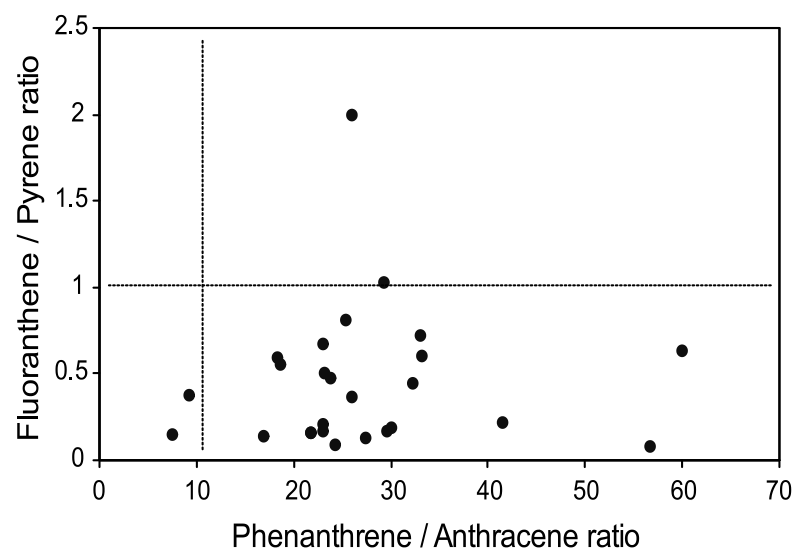

Fig. 1. Plots between the ratio of Phe/Ant (phenanthrene vs. anthracene) and Flu/Pyr (fluoranthene vs. pyrene) for sample areas to attempt delineation of petrogenic and pyrogenic sources. (Phe/Ant $<10$, Flu.Pyr $>1$ : Pyrolytic origin, Phe/Ant $>10$, Flu/Pyr $<1$ : Petrogenic origin).

\section{$\mathrm{PAHs}$ 의 근원}

$\mathrm{PAHs}$ 는 주로 3 가지 과정을 통해 생성된다. 첫째 연소기원, 둘째 석유 기원 그리고 세 번째 생물과정이나 인간 활동에 의해 생성된다고 보고하였다 (Neff, 1979). 일반적으로 탄화수 소의 기원 규명은 개별 탄화수소 분자의 함량에 근거한 "지문 (fingerprint) "을 이용한다 (Gschwend and Hites, 1981). 따라서 많은 연구자들은 여러 함량비를 바탕으로 기원을 구분하고 있다. 본 연구에서는 phenanthrene / anthracene, fluoranthene / pyrene 의 함량비를 조사하여 Fig. 1에 나타내었다. Phenanthrene / anthracene $>15$, fluoranthene / pyrene $<1$ 의 비를 가지면 석유기원에 가깝다고 요약 보고되어있다 (Benner et al., 1989; Budzinski et al., 1997; Readman et al., 2002; Ying et al., 2003). 자세한 기원 구분을 위해서는 분자지수들을 상세 하게 조사하여야 할 것이지만 이번 조사에서는 Readman 등 (2002)이 사용한 방법으로 PAHs의 기원을 분석한 결과 대부분 의 시료에서 Phe/Ant 비율이 15 이상이고 Fla/Pyr의 1 이하를 나타내어 이번 조사 지역에서 채취한 양식패류의 PAHs 성분 들은 석유기원이 열기원에 비해 우세한 것으로 나타나 원유 유출 사고의 영향을 받은 것으로 판단되어진다.

유류유출 사고해역 패류중의 위해도 평가

내분비계 장애 물질로 알려진 PAHs 화합물 중 벤조피렌은 석유, 가솔린, 식물 등 유기물질의 연소에 의해 생성되므로 가장 일반적으로 연구 되고 있다 (Kszerouni et al., 2002). 인간 은 주로 음식 섭취를 통해 $\mathrm{PAHs}$ 에 많이 노출되고 있는데 PAHs 오염의 주요 원천 중 하나는 석유 또는 타르 제품과의 접촉을 통해서이다 (IARC, 1985). 패류에 PAHs가 축적되면 그 패류를 섭취하는 사람에게 암을 발생 시킬 수 있기 때문에 (Hecht et al., 1976; Clement, 1988; OEHHA, 2005) 유류유출사 고에 의해서 오염된 해역에서 가장 많이 생산되는 굴과 바지 락의 오염도를 조사하여 그 위해도를 평가하였다. 위험 표준 기준에서 인체의 위험을 막기 위해 최대 수용 가능한 위험 수준 (RL)을 $1 \times 10^{-6}$ 으로 정하였고 (US EPA, 2000), 수산물 중 $\mathrm{PAHs}$ 오염농도는 벤조피렌으로 환산된 $\mathrm{TEQ}$ 를 적용하였 다. 수산물 섭취량은 국민건강영양조사보고서 (2005)에 의거 1 일 평균 어패류 섭취량 $86 \mathrm{~g}$ 으로 하였으며, 평균체중은 남녀 평균 값인 $60 \mathrm{~kg}$ 을 적용하면 굴 섭취에 의한 초기발암 위해도 는 $1.31 \times 10^{-8}$, 바지락에 의한 초기발암 위해도는 $6.9 \times 10^{-9}$ 이다 (Table 4).

Table 4. Lifetime cancer risks from dietary intake of contaminated oysters and short neck clams in this study

\begin{tabular}{cc}
\hline Sellfish & Lifetime cancer risk \\
\hline Oyster & $1.31 \times 10^{-8}$ \\
Short neck clam & $6.9 \times 10^{-9}$ \\
\hline
\end{tabular}

Moon et al. (2004)은 우리나라 연안 수산물에 대한 발암 위해도를 어류, 갑각류, 이매패류가 두족류나 복족류보다 수 
치가 높게 나왔으며 각각의 수치는 어류 $2 \times 10^{-7}$, 갑각류 $1 \times$ $10^{-7}$, 이매패류 $4 \times 10^{-7}$ 이고 두족류는 $7 \times 10^{-8}$, 복족류는 $8 \times 10^{-9}$ 으 로 발표하였다. 이번 서해안 원유 유출사고 해역의 패류에 대한 안전성 조사에서는 굴 $1.31 \times 10^{-8}$, 바지락 $6.9 \times 10^{-9}$ 으로 굴이 바지락에 비해 높았지만, 서해안에서 채취한 패류 섭취 로 인한 인체 발암 위해도는 매우 낮은 것으로 추정된다. 또한 PAHs 기원분석을 통하여 서해안의 패류는 유류 오염으 로 인해 PAHs가 발생된 것으로 밝혀졌지만 수산물 안전성 평가에서 인체에는 큰 영향을 끼치지 않을 정도의 수준이었 다. 또한 $\mathrm{EU}$ 의 이매패류에 대한 벤조피렌의 권장규격 $10 \mathrm{ppb}$ 를 초과한 시료도 발견되지 않아, 서해안 패류에 대하여 패류 섭취량 및 독성 등을 고려할 때 위해 발생 우려는 낮을 것으로 생각된다. 그러나 원유유출 사고해역에서는 장기적으로 생물 에 영향을 끼치는 것으로 알려져 있기 때문에 우리나라 서해 안의 수산물에 대해서도 지속적인 모니터링을 통하여 수산물 의 안정성을 확인할 필요가 있다고 생각되어진다.

$$
\text { 사 사 }
$$

본 연구는 국립수산과학원 태안어장 정밀조사 및 복원사업 의 연구비지원에 의해 수행되었습니다 (RP-2008-FS-009).

\section{참고문헌}

Benner BA, Gordon GE and Wise SA. 1989. Mobile sources of atmospheric polycyclic aromatic hydrocarbons-A roadway tunnel study. Environ Sci Technol 23, 1269-1278.

Bingham E and Falk HL. 1969. The modifying effect of carcinogens on the threshold response. Arch Environ Health 19, 779-783.

Boehm PD and Farrington JW. 1984. Aspects of the polycyclic aromatic hydrocarbon geochemistry of recent sediments in the Georges Bank region. Environ Sci Technol 18, 840-845.

Budzinski H, Jones I, Bellocq J, Pierard C and Garrigues P. 1997. Evaluation of sediment contamination by polycyclic aromatic hydrocarbons in the Gironde estuary. Mar Chem 58, 85-97.

Busby WF, Jr. Stevens EK, Martin CN, Chow FL and Garner RC. 1989. Comparative lung tumorigenicity of parent and mononitro-polynuclear aromatic hydrocarbons in the BLU: Ha newborn mouse assay. Toxicol Appl Pharmacol 99, 555-563.

CDHS, California Department of Health Services. 1985. Guidelines for Chemical Carcinogen Risk. Health and Welfare Agency, Sacramento CA.

Cavalieri EL, Rogan EG, Higginbotham S, Cremonesi P and Salmasi S. 1989. Tumor -initiating activity in mouse skin and carcinogenicity in rat mammary gland of dibenzo(a)pyrenes: the very potent environ- mental carcinogen dibenzo(a)pyrene. J Cancer Res Clin Oncol 115, 67-72.

Clement Associates. 1988. Comparative Potency Approach for Estimating the cancer risk associated with exposure to mixture of polycyclic aromatic hydrocarbons(Interim final report). Prepared for EPA under contact 68-02-4403. ICF-Clement Associates, Fairfax, VA.

EC, European Commission. 2002. Opinion of the scientific committee on food in the risks to the human health of polycyclic Aromatic Hydrocarbons in food $\mathrm{SCF} / \mathrm{CS} / \mathrm{CNTM} / \mathrm{PAH} / 29$ final, 1-84.

Gelboin HV. 1980. Benzo(a)pyrene metabolism, activation, and carcinogenesis: Role and regulation of mixed-function oxidases and related enzymes. Physiol Rev 60, 1107-1166.

Gold L, de Veciana M, Backman G, Magaw R, Lopipero P, Smith M, Blumenthal M, Levinson R, Bernstein L and Ames B. 1986. Chronological supplement to the carcinogenic potency database: standardized results of animal bioassays published through December 1982. Environ Health Perspect 67, 161-200.

Gschwend PM and Hites RA. 1981. Fluxed of the polycyclic aromatic hydrocarbons to marine and lacustrine sediments in the north-eastern United States. Geochim Cosmochim Acta 45, 2359-2367.

Hecht SS, Loy M, Maronpot RR and Hoffman D. 1976. A study of chemical carcinogenesis: comparative carcinogenicity of 5-methylchrysene, benzo(a)pyrene, and modified chrysenes. Cancer Lett 1, 147-154.

IARC (International Agency for Research on Cancer). 1983. Benzo[a]pyrene. In: Polynuclear Aromatic Compounds, Part 1, Chemical, Environmental and Experimental Data. Vol. 32, 211-224.

IARC (International Agency for Research on Cancer). 1985. Polynuclear Aromatic Compounds Part 4. Bitumens, Coal-Tars and Derived Products, ShaleOils and Soots, Vol. 35, 83-86.

Kazerouni N, Sinha R, Hsu CH, Greenberg A and Rothman N. 2002. Anaysis of 200 food items for benzo[a]pyrene and estimation of its intake in an epidemiologic study. Food Chem Toxicol 39, 423-436.

Kelly C, Santillo D, Johnston P, Fayad G, Baker KL and Law RJ. 2008. Polycyclic aromatic hydrocarbons in oysters from coasta waters of the Lebanon 10 months after the Jiyeh oil spill in 2006. Mar Pollut Bull 56, 1215-1233.

Kim GB, Maruya KA, Lee RF, Lee JH and Koh CH. 1999. Distribution and sources of polycyclic aromatic hydrocarbons in sediments from Kyeonggi Bay 
Korea. Mar Pollut Bull 38, 7-15.

Law RJ and Biscaya JL. 1994. Polycyclic aromatic hydrocarbons (PAHs) - problems and progress in sampling, analysis and interpretation. Mar Pollut Bull 29, 235-241.

Law RJ, Kelly CA, Baker KL, Langfod KH and Bartlrtt T. 2002. Polycyclic aromatic hydrocarbons in sediments, mussels and crustacea around a former gasworks site in Shoreham-by-Sea, UK. Mar Pollut Bull 44, 903-911.

Lee RF and Page DS. 1997. Petroleum hydrocarbons and their effectrs in subtidal regions after major oil spills. Mar Pollut Bull 34, 928-940.

Neff JM. 1979. Polycyclic aromatic hydrocarbons in the aquatic environment, sources, fats and biological effects. Applied Science, London, U.K., 262.

Ministry of Health and Welfare. 2005. The third Korea national health \& nutrition examination survey (KNHANES III), 2005 - nutrition survey ( I ), 139142.

Moon HB, Choi HG, Kim SS, Jeong SR, Lee PY and Ok G. 2001. Monitoring of polycyclic aromatic hydrocarbons in sediments and organisms from korean coast. J Fish Sci Tech 4, 219-228.

Moon HB, Lee SJ and Park JS. 2004. Dietry intake and potencial health risk of polycyclic aromatic hydrocarbons (PAHs) via various marine organisms korea. J Fish Sci Tech 7, 141-147.

OEHHA (Office of Environmental Health Hazard). 2005. Air toxics hot spots program risk assessment guidelines. Part $\Pi$. Technical support document for describing available cancer potency factors. Mar Environ Res 59, 453-472.

Pelkonene O and Nebert DW. 1982. Metabolism of polycyclic aromatic hydrocarbons. Etiological Role in carcinogenesis Pharmacol Rev 43, 198-222.

Petry T, Schmid P and Schlatter C. 1996. The use toxic equivalency factors in assessing occupational and environmental health risk associated with exposure to airborne mixtures of polycyclic aromatic hydrocarbons (PAHs). Chemosphere 32, 632-648.

Potter TL and Simmons KE. 1998. Total petroleum hydrocarbon criteria working group seriescomposition of petroleum mixtures. Vol. 2. USA chemico-biological interactions 59, 309-324.

Readman JW, Fillmann G, Tolosa I, Bartocci J, Villeneuve JP, Catinni C and Mee LD. 2002. Petroleum and PAH contamination of the black sea. Mar Pollut Bull 44, 48-62.
Speer K, Steeg E, Horstmann P, Kuhn TH and Montag A. 1990. Determination and distribution of polycyclic aromatic hydrocarbons in native vegetable oils, smoked fish products, mussels and oysters, and bream form the river Elbe. J High Resol Chromat 13, 104-111.

Tsai PJ, Shieh HY, Lee WJ and Lai SO. 2001. Health-risk assessment for workers exposed to polycyclic aromatic hydrocarbons(PAHs) in a carbon black manufacturing industry. Sci Total Environ 278, 137-150.

US EPA (Environmental Protection Agency). 1979. Health assessment document for polycyclic organic matter. EPA 600/9-79-008. Office of Health and Environmental Assessment, Research Triangle Park, NC.

US EPA (Environmental Protection Agency). 1988. Recommendations for and documentation of biological values for use in risk assessment. EPA 600/6-87/008. Office of Health and Environmental Assessment, Cincinnati, $\mathrm{OH}$.

US EPA (Environmental Protection Agency). 1993. Integrated risk information system(IRIS): Benzo[a] pyrene. Office of Research and Development, National Centerfor Environmental Assessment, Washington, 251-269.

US EPA (Environmental Protection Agency). 2000. Guideline for Assessing Chemical Contaminant Data for Use in Fish Advisories. Volume 2. Risk Assessment and Fish Consumption Limits. 3rd Ed. EPA 823-B-00-007.

US EPA (Environmental Protection Agency). 2004. Risk-based concentration table. Itegrated risk information system (IRIS). US. EPA, Philadelphia, RA.

WHO (World Health Organization). 1995. Recommendations for the revision of guidelines for predicting dietary intake of pesticide residues. In Report of a FAO/WHO consultation (WHO/FNU/FOS) Otolaryngology-Head and Neck Surgery 112, 308-315.

Ying WU, Zhang J and Zhijian Z. 2003. Poycyclic aromatin hydrocarbons in the sediments of the Yalujiang Estuary, North China. Mar Pollut Bull 46, 619-625.

2009년 6월 3일 접수

2010년 5월 12일 수정

2010년 6월 10일 수리 